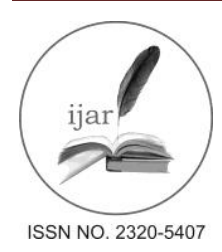

Journal homepage: http://www.journalijar.com

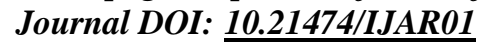

RESEARCH ARTICLE

\title{
CANONICAL CORRESPONDENCE ANALYSIS AND PATH ANALYSIS MODEL (CCA) APPLIED TO DENTAL CARIES AMONG CHILDREN SIX AND SEVEN YEAR OLDS, BACHOK, KELANTAN, MALAYSIA.
}

\author{
Ruhaya Hasan ${ }^{1}$, Wan Muhamad Amir W Ahmad ${ }^{1}$, Nor Affendy Nor Azmi ${ }^{1}$, Rosmaliza Ramli ${ }^{1}$, Nurhafizah \\ Ghani $^{1}$, Zailani Abdullah ${ }^{2}$, Nor Azlida Aleng ${ }^{3}$, Nurfadhlina Abdul Halim ${ }^{3}$, Syerrina Zakaria ${ }^{3}$, , Kasypi \\ Mokhtar ${ }^{4}$. \\ 1. School of Dental Sciences, Health Campus, Universiti Sains Malaysia (USM), 16150 Kubang Kerian, Kelantan, \\ Malaysia. \\ 2. Faculty of Entrepreneurship and Business,Universiti Malaysia Kelantan (UMK),16100Pengkalan Chepa, \\ Kelantan. \\ 3. School of Informatics and Applied Mathematics, Universiti Malaysia Terengganu (UMT), 21030 Kuala \\ Terengganu, Terengganu. \\ 4. School of Maritime Business and Management, Universiti Malaysia Terengganu (UMT), 21030 Kuala \\ Terengganu, Terengganu.
}

Manuscript Info

Manuscript History:

Received: 17 March 2016

Final Accepted: 02 May 2016

Published Online: May 2016

Key words:

Canonical correspondence analysis,

Path analysis, dental caries and

logistic regression.

*Corresponding Author

Ruhaya Hasan.

\begin{abstract}
A correspondence analysis and path analysis approach were conducted for a dental caries case study among 6-7 year-old children from (Bachok District) Kelantan. Data from382 children were collected and caries status was examined visually by two dental officers from School of Dental Sciences, Hospital Universiti Sains Malaysia (HUSM). All related and important information observed was recorded in a research form. Results showed that $63.1 \%$ of the children was in high caries category. The incidence of caries among these children was very high and required attention from the government. The factors associated with caries status were analyzed using graphical mapping approach and path model analysis. This statistical technique facilitated the visualization through mapping procedure and path modeling analysis of the studied variables. All data were processed and analyzed using SAS (for Canonical Correspondence Analysis) and SPSS (Logistic Regression) software.
\end{abstract}

Copy Right,IJAR, 2016... All rights reserved..

\section{Introduction to dental caries among children:-}

Dental caries among children is a disease with multi factorial causes. Previous studies showed that the prevalence and incidence of dental caries in a population is influenced by a number of risk factors such as age, sex, ethnic, body mass index (BMI), dietary patterns and oral hygiene habits (Sudha, Bhasin \& Anegundi, 2005;Sadeghi \& Alizadeh, 2007; Hilgers, Kinane \& Scheetz, 2006). In many countries in Asia, children have limited access to dental care, although general health care service at the hospital or clinic, for example, may be generally available. This leads to the increase of prevalence of dental caries and oral diseases, particularly during childhood (Amir et al., 2016).According to Moses et al., (2011) and American Academy of Pediatric Dentistry (2002-2015), dental caries causes tooth pain, anxiety, eating impairment, and tooth loss among children. These conditions affect the children's concentration in learning and become a financial burden to their families. Erika et al., 2013, used chi-square tests to compare socio demographic differences of children stratified by caries and no caries status as well as three levels of caries severity. They found that older age, no or public dental insurance and rural residential location were associated with higher cases of untreated dental caries. Another study looking at the association between body weight and dental caries reported that children with normal weight were caries free, whereas only $14 \%$ of children at risk of overweight and $37.2 \%$ of the overweight children were caries free. There was statistically significant 
association between BMI-for-age and being caries free (Mostafa \& Farnosh, 2007). This study involved dental examination and data collection of all selected 6-7 year-old children in Bachok, Kelantan (Amir et al., 2016). All selected parameters were summarized in Table 1. We aimed to investigate the factors associated with caries status by using canonical correspondence analysis (also known as biplot analysis) with respect to all categorical variables. Data were analyzed using SAS software for the canonical correspondence. In this study, we built prior algorithm to find the graphical mapping approached (CCA). We applied CCA in order to discover the relationship between caries status and all related categories' variables. CCA exposes the multidimensional structure inherent in the data based on pairwise frequency tables. The principle result of CCA is a graphical display called biplot and it is given by a two-dimensional map. From the graphical displays, the associated factors were grouped closely, according to the characteristics of their categories variables (Amir et al., 2016).

Table1:- Description ofdata among preschool children in Bachok, Kelantan, Malaysia

\begin{tabular}{|c|c|c|}
\hline Num. & Variables & Explanation of user variables \\
\hline 1. & Deft & $\begin{array}{l}\text { Caries Status } \\
0=\text { No } \\
1=\text { Low } \\
2=\text { Moderate } \\
3=\text { High } \\
\end{array}$ \\
\hline 2 & CatWAZ & $\begin{array}{l}\text { Category of weight-for-age } \\
1=\text { Underweight } \\
2=\text { Severe Underweight } \\
3=\text { Normal } \\
4=\text { Overweight } \\
5=\text { Obese }\end{array}$ \\
\hline 3 & EduM & $\begin{array}{l}\text { Education level of mother } \\
1=\text { Do not school } \\
2=\text { Up to standard } 6 \\
3=\text { Form } 1 \text { to Form } 5 \\
4=\text { Form } 6, \text { Colleges } \\
\quad \text { and Diploma } \\
5=\text { University Degree } \\
\text { and Above }\end{array}$ \\
\hline 5 & Astatus & $\begin{array}{l}\text { Attitudetowards of dental caries } \\
1=\text { Poor } \\
2=\text { Moderate } \\
3=\text { Good }\end{array}$ \\
\hline
\end{tabular}

\section{Sample size, materials and methods:-}

Sample Size Determination:-

Sample size for multiple regression analysis were calculated by using $\mathrm{G}^{*}$ power with effect size $=0.02, \alpha=0.05$, power of the study $=0.68$ and number of predictor were three. The minimum sample size requires is 372 respondents.

\section{Canonical correspondence analysis and chi-square analysis:-}

In this section, we used two statistical approaches to analyze the dataset. Firststatistical approach wascorrespondence analysis through the biplot. Correspondence analysis is an exploratory data technique used to analyze categorical data (Benzeri,1992). Canonical correspondence analysis is a mapping technique used to analyze data because of its ability to extract the most important dimensions, allowing simplification of the data matrix (Palmer, 1993). This technique allows us to investigate the relationship between two nominal variables graphically in a multidimensional space (Amir, 2010; Amir, 2011). It computes row and column scores and produces plots based on the scores. Categories that are similar to each other appear close to each other in the plot. 


\section{Results and discussion:-}

Case I: Correspondence Analysis for Caries Status with Different Categories of Weight for Age.

Output for CCA:-

Table 2:- CrosstabulationAnalysis between Caries Status and Category of Weight for Age

\begin{tabular}{|l|c|c|c|c|}
\hline Variables & \multicolumn{4}{|c|}{ Caries Status n(\%) } \\
\hline Category of weight for age & No Caries & Low & Moderate & High \\
\hline Under weight & 10 & 15 & 22 & 83 \\
& $(7.7 \%)$ & $(11.5 \%)$ & $(16.9 \%)$ & $(63.8 \%)$ \\
\hline Severely under weight & 0 & 8 & 17 & 65 \\
& $(0 \%)$ & $(8.9 \%)$ & $(18.9 \%)$ & $(72.2 \%)$ \\
\hline Normal & 10 & 20 & 39 & 93 \\
& $(6.2 \%)$ & $(12.3 \%)$ & $(24.1 \%)$ & $(57.4 \%)$ \\
\hline
\end{tabular}

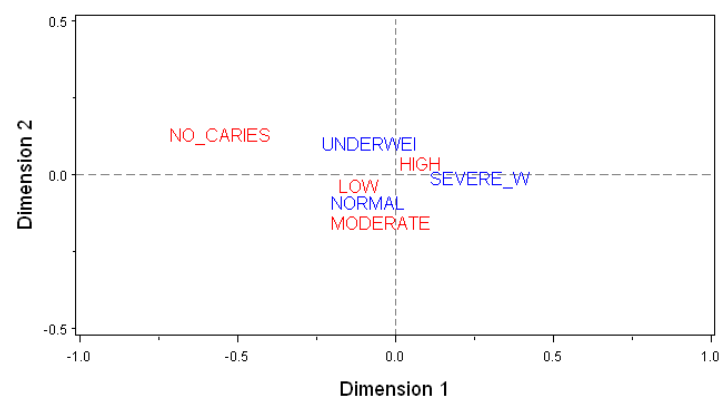

Figure 1:- Biplot Analysis of Caries Status with Category of Weight by Age.

Biplot technique, allows us to investigate the relationship between two nominal variables graphically in a multidimensional space (Amir, 2011). Our results showed that high caries status occurred mostly among children who were underweight and severely underweight (see Figure 1). A study conducted by Bud et.al, 2015 found that the underweight group presented a significantly higher DMFT (Decayed, Missing Filled Teeth) index compared to normal weight, overweight and obese, while most of the low caries and moderate caries occurred among children who had normal weight. According to Amandeep Chopra et al., (2015), the underweight, overweight, and obese children are 2.7, 2.5, and 3 times at risk of developing caries as compared to children with normal BMI respectively.

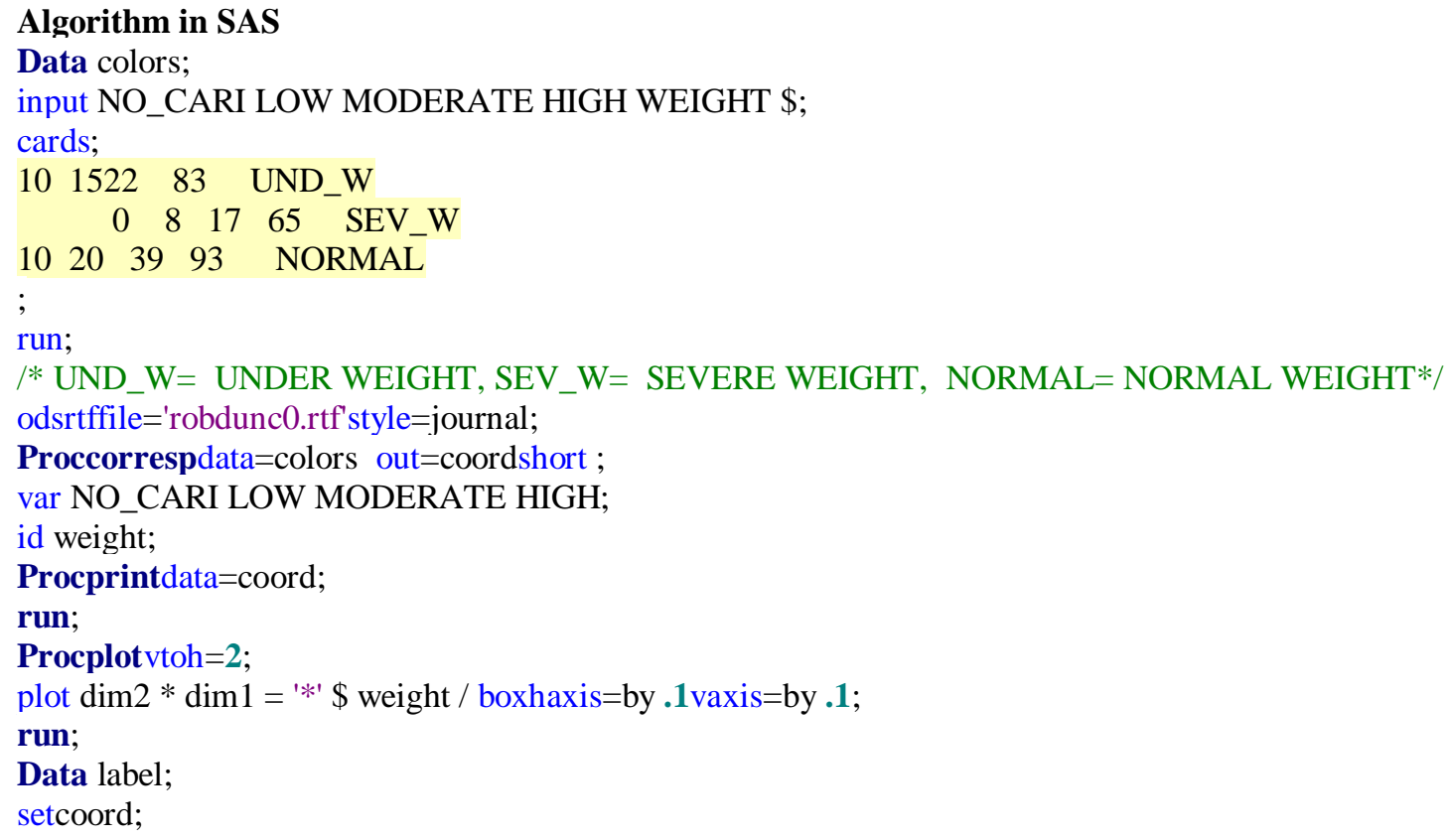




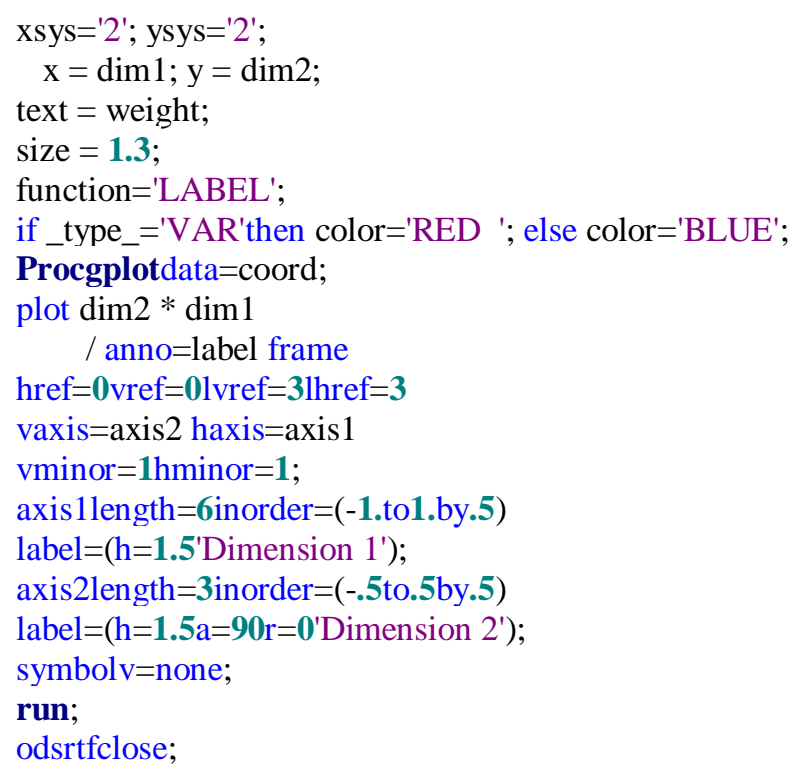

Section II. Correspondence Analysis for Caries Status with Education level of the Mother. Output for CCA:-

Table 3:- Cross tabulation Analysis between Caries Status and Level of Education of the Mother

\begin{tabular}{|c|c|c|c|c|}
\hline Variables & \multicolumn{4}{|c|}{ Caries Status n(\%) } \\
\hline Education level of Mother & No Caries & Low & Moderate & High \\
\hline No formal education & $\begin{array}{c}0 \\
(0 \%)\end{array}$ & $\begin{array}{c}0 \\
(0 \%)\end{array}$ & $\begin{array}{c}1 \\
(20 \%)\end{array}$ & $\begin{array}{c}4 \\
(80 \%)\end{array}$ \\
\hline Up to standard 6 & $\begin{array}{c}1 \\
(5 \%)\end{array}$ & $\begin{array}{c}1 \\
(5 \%)\end{array}$ & $\begin{array}{c}6 \\
(30 \%)\end{array}$ & $\begin{array}{c}12 \\
(60 \%)\end{array}$ \\
\hline Form 1 to Form 5 & $\begin{array}{c}10 \\
(5.5 \%)\end{array}$ & $\begin{array}{c}20 \\
(8.83 \%)\end{array}$ & $\begin{array}{c}39 \\
(19.0 \%)\end{array}$ & $\begin{array}{c}93 \\
(66.8 \%)\end{array}$ \\
\hline Form 6, College and Diploma & $\begin{array}{c}2 \\
(3.5 \%)\end{array}$ & $\begin{array}{c}13 \\
(22.8 \%)\end{array}$ & $\begin{array}{c}14 \\
(24.6 \%)\end{array}$ & $\begin{array}{c}28 \\
(49.1 \%)\end{array}$ \\
\hline University Degree and Above & $\begin{array}{c}2 \\
(7.7 \%)\end{array}$ & $\begin{array}{c}5 \\
(19.2 \%)\end{array}$ & $\begin{array}{c}5 \\
(19.2 \%)\end{array}$ & $\begin{array}{c}14 \\
(53.8 \%)\end{array}$ \\
\hline
\end{tabular}

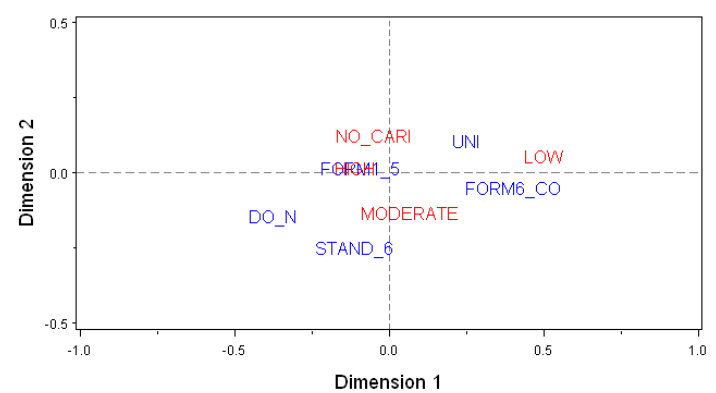

Figure 2:- Biplot Analysis of Caries Status among Children with Education Level of the Mother.

Majority of high and moderate caries status occurred among those children whose mothers did not have any formal education or having education only up to secondary level (form 1 to form 5). Meanwhile mothers with tertiary education (diploma, collages and university level)had children with low caries status. 


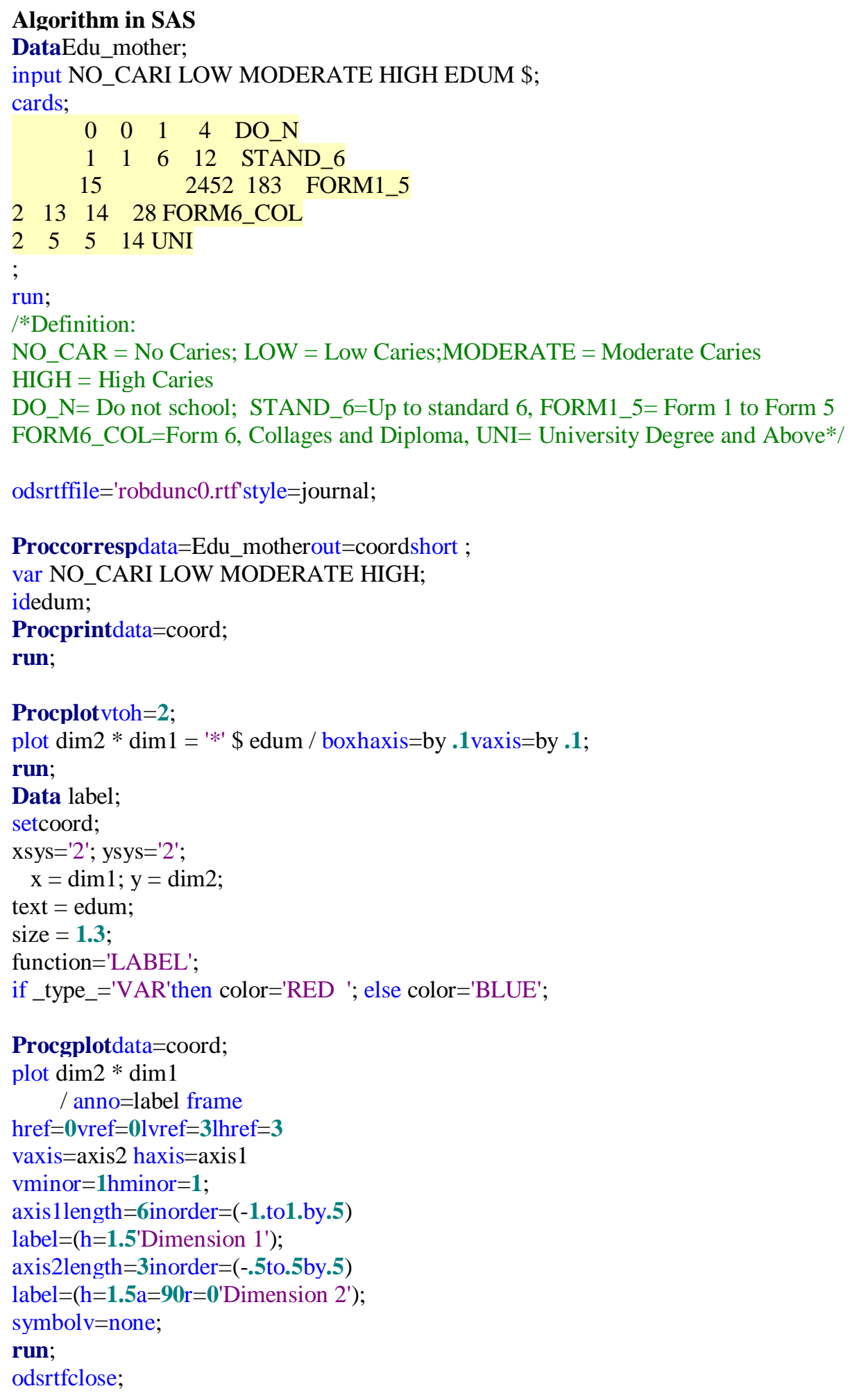


Section III. Correspondence Analysis for Caries Status with Attitudes towards Dental Caries

Output for CCA:-

Table 4:- Cross tabulation Analysis between Caries Status and attitudes towards dental caries

\begin{tabular}{|l|c|c|c|c|}
\hline Variables Code & \multicolumn{4}{|c|}{ Caries Status n(\%) } \\
\hline Attitude towards dental caries & No Caries & Low & Moderate & High \\
\hline Poor & 2 & 1 & 11 & 28 \\
& $(4.8 \%)$ & $(2.4 \%)$ & $(26.2 \%)$ & $(66.7 \%)$ \\
\hline Moderate & 12 & 34 & 54 & 175 \\
& $(4.4 \%)$ & $(12.4 \%)$ & $(19.6 \%)$ & $(63.6 \%)$ \\
\hline Good & 6 & 8 & 13 & 38 \\
& $(9.2 \%)$ & $(12.3 \%)$ & $(20.0 \%)$ & $(58.5 \%)$ \\
\hline
\end{tabular}

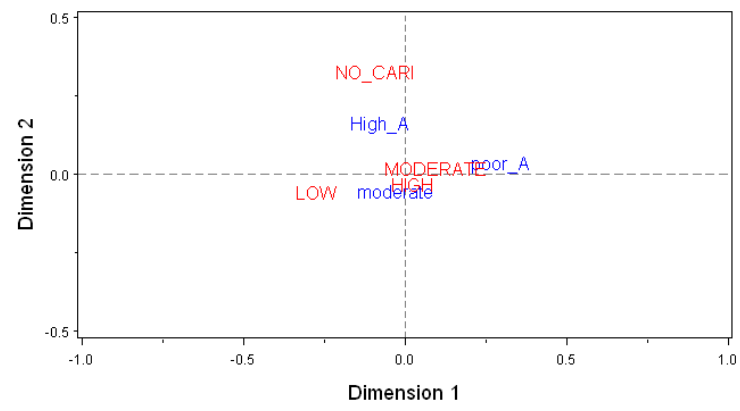

Figure 3:- Biplot Analysis of Caries Status and Attitude towards Dental Caries.

Poor attitude and moderate attitude are near the high caries status while good attitude is closest to no caries. This results show that parents have a direct involvement in ensuring their children's oral health. Parents who have high awareness towards proper dental care play an important role in maintaining the oral health, and may contribute in reducing the incidence of tooth decay among their children.

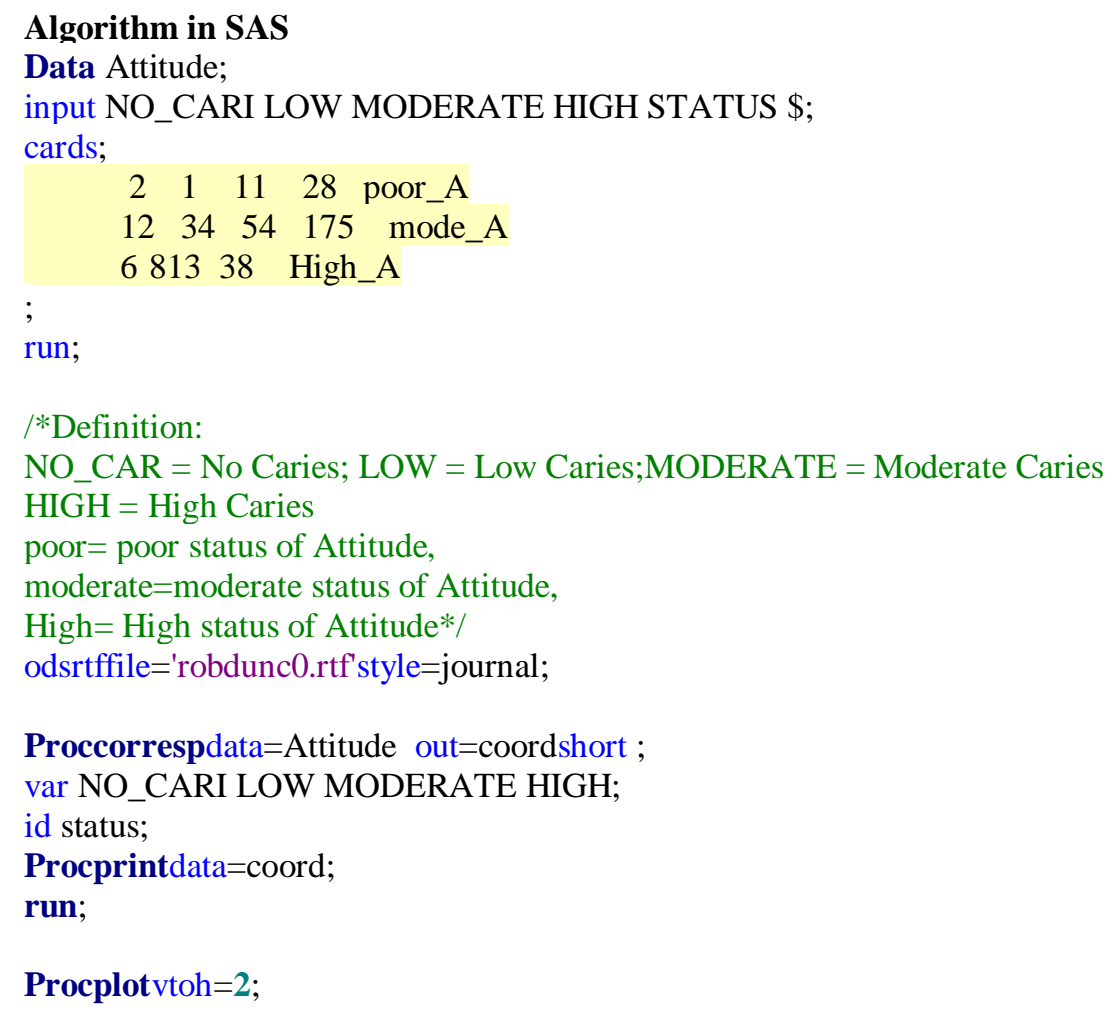

Proccorrespdata=Attitude out $=$ coordshort ; var NO_CARI LOW MODERATE HIGH; 
plot $\operatorname{dim} 2 * \operatorname{dim} 1={ }^{\prime *} \$$ status $/$ boxhaxis=by .1vaxis=by .1;

run;

Data label;

setcoord;

xsys='2'; ysys='2';

$\mathrm{x}=\operatorname{dim} 1 ; \mathrm{y}=\operatorname{dim} 2$;

text $=$ status;

size = 1.3;

function='LABEL';

if_type_='VAR'then color='RED '; else color='BLUE';

Procgplotdata $=$ coord;

plot $\operatorname{dim} 2 * \operatorname{dim} 1$

/ anno=label frame

href $=0$ vref $=01$ vref $=31$ href $=3$

vaxis $=$ axis 2 haxis $=$ axis 1

vminor $=1 \mathrm{hminor}=\mathbf{1}$;

axis1length $=6$ inorder $=(-1$. to1.by.5)

label $=\left(\mathrm{h}=1.5{ }^{\prime}\right.$ Dimension $\left.1^{\prime}\right)$;

axis2length $=3$ inorder $=(-.5$ to.5by.5)

label $=\left(\mathrm{h}=\mathbf{1 . 5 a}=\mathbf{9 0} \mathrm{r}=\mathbf{0}^{\prime}\right.$ Dimension $\left.2^{\prime}\right)$;

symbolv=none;

run;

odsrtfclose;

\section{Case II:- Path Analysis Model for Caries Status}

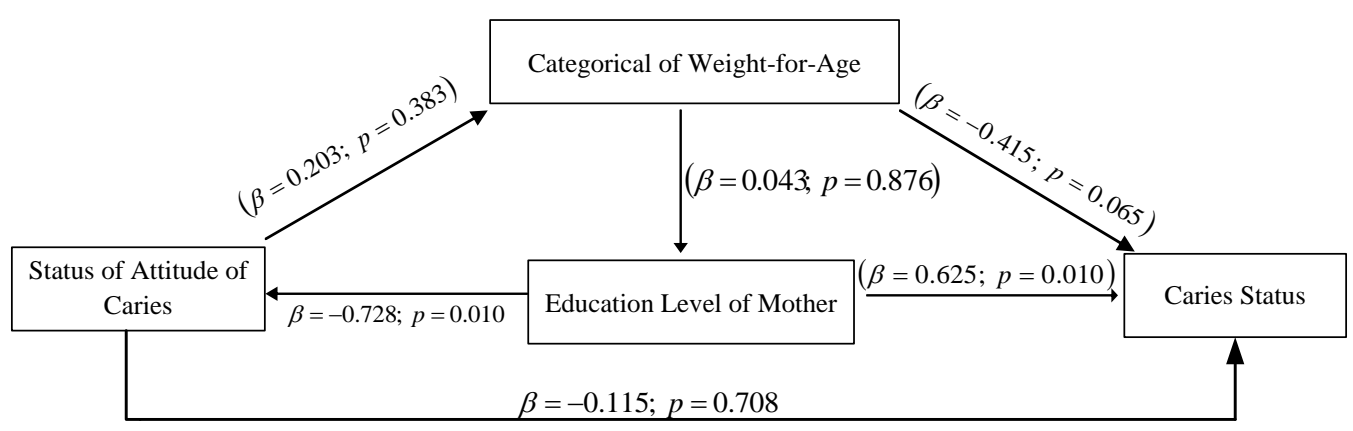

Figure 4:- Structural Equation Modeling using Logistic Regression Modeling.

A model was conducted based on the logistic regression. The model consists of four major items, caries status, category of weight for age, attitude towards dental caries, and education level of the child's mother. From the path model there were two major factors that contributed to the caries status among children. The first factor was education level of mother $(\beta=0.625 ; p=0.010)$ and the second factor was category of weight for age $(\beta=-0.415 ; p=0.065)$. The path analysis modeling showed the factors that contributed to the incidence of caries among preschool children in Bachok. From the model, we can see clearly that score factor has direct and indirect effect son the caries status. According to the American Academy of Pediatric Dentistry 2014, tooth decay is the single most common chronic childhood disease, five times more common than asthma, four times more common than early childhood obesity, and 20 times more common than diabetes. This path analysis modelling tells us that some of the studied factors can be controlled at the level of education of mother and parent's attitude towards dental caries(see Figure 4). All possible lines that can represent the caries status have been proposed to the caries status among the school children 


\section{Summary and conclusion:-}

The focus of this study was to find the factors that lead to dental caries from a different point of view. Biplot analysis approach between caries status and the categories of weight for age was carried out. The results showed that high caries status occurred mostly among children who were underweight and severely underweight. Second biplot analysis was conducted between caries status and level of education of mother. The results showed that children whose mothers had no formal education or education only up to secondary level (form 1 to form 5) had high and moderate caries status.

Meanwhile, mothers who had diploma or degree from college or university had children with lower caries status as compared to the other groups. The third biplot analysis showed that poor attitude and moderate attitude were near the high caries status while good attitude were closest to no caries. These results indicate that parents with good attitude towards dental caries can play a major role in preventing their children from having dental caries. The second approach was carried out using logistic regression analysis. From the output gained, we performed a path model (also known as a structural equation modeling (SEM). This paper proposes a path logistic regression model which can be used to make a prediction on the caries status. It gives a comprehensive information and general idea on the relationship between caries status and the factors studied. This path model provides a preliminary overview of the problems associated with dental caries.

\section{References:-}

1. American Academy of Pediatric Dentistry (2002-2015). Early Childhood Caries (ECC).Availablefrom:http://www.aapd.org/resources /parent_resources /[28 September 2015].

2. Chopra, A.Rao, N.C., Gupta, N., Vashisth, S., and Lakhanpal, M.(2014). The Predisposing Factors between Dental Caries and Deviations from Normal Weight. N Am J Med Sci. Apr; 7(4): Pp.151-159

4. Moses J, Rangeeth B.N, Gurunathan D. (2011). Prevalence of dental caries, socio-economic old school going children of chidambaram status and treatment needs among 5 to 15 year old school going children Of Chidambaram. J ClinDign Res.5:146-151.

5. Sadeghi M, Alizadeh F. (2007). Association between Dental Caries and Body Mass Index-For-Age among 611-Year-Old Children in Isfahan in 2007. J Dent Res.;1(3):119-124.

6. Hilgers K.K., Kinane D.E, Scheetz J.P. (2006). Association between childhood obesity and smooth-surface caries in posterior teeth: a preliminary study. Pediatr Dent. Jan-Feb;28(1):23-8

7. Amir W.M.W.A., Azlida, A., Norizan, M. (2011). Statistical Test for Research Using SPSS. PenerbitUniversiti Malaysia Terengganu.

8. Amir W.M.W.A., Mustafa M. (2009). Data Analysis Using SPSS: A Technical Aprroach.PenerbitUniversiti Malaysia Terengganu.

9. Amir W.M.W.A, Ruhaya H., Nor Azlida A., Nurfadhlina A.H., Syerrina Z. and Zalila A. .(2016). Effects of Food Expenses and Tooth Filling towards Dental Caries among Children in Bachok, Kelantan, Malaysia: 3-D Surface Plots Approached. Journal Clinical and Experimental Medical Sciences. Vol. 4. Pp. 1-7

10. Sudha P, Bhasin S, Anegundi RT.(2005) Prevalence of dental caries among 5-13-year-old children of Mangalore city. J. Indian Soc.PedodPrevDent;23:74-9

11. Mostafa S., Farnosh A. (2007). Association Between Dental Caries And Body Mass Index-For-Age Among 611- Year-Old Children In Isfahan In 2007. Journal of Dental Research, Dental Clinics, Dental Prospects. Vol .1(3): Pp119-124.

12. 12.Benzecri, J.-P. (1992). Correspondence Analysis Handbook. New York: Marcel Decker.

13. Palmer, M. W. (1993). Putting things together in even better order: The advantages of canonical correspondence analysis. Ecology, 74, 2215-2230.

14. American Academy of Pediatric Dentistry (2002-2015). Early Childhood Caries (ECC).Available from: http://www. aapd.org/ resources/ parent_resources /[28 September 2015].

15. 15.Erika, D., Michimi, A, Ellis-Griffith, G., Peterson, T., Carter, D., and English, G. (2013). Dental caries among children visiting a mobile dental clinic in South Central Kentucky: a pooled cross-sectional study. BMC Oral Health. 13:19. 